\title{
Essay \\ Thoughts on Publishing the Research Article over the Centuries
}

\author{
David Banks \\ Faculté des Lettres et Sciences Humaines, Université de Bretagne Occidentale, 20, rue Dusquesne, \\ 29238 Brest, France; David.Banks@univ-brest.fr
}

Received: 20 January 2018; Accepted: 5 March 2018; Published: 8 March 2018

\begin{abstract}
The first academic periodical was the Journal des Sçavans, which first appeared in January 1665. It was followed two months later by the Philosophical Transactions. The Journal des Sçavans was sponsored by the state and was made up mainly of book reviews and covered all the known disciplines of the time. The Philosophical Transactions was a private venture based on Oldenburg's correspondence and was restricted to science and technology. Scientific writers were motivated by personal reputation, the desire to improve the human condition, and, sometimes, priority. The "publish or perish" syndrome is a recent development. Among the factors that have influenced it are the increasing professionalization of science, the development of the peer-review system, and, towards the end of the twentieth century, a desire for rapid publication. The fact that English has (recently) become the lingua franca of scientific publishing creates additional difficulties for non-Anglophone scientists, which their Anglophone colleagues do not have to face. Scientific language, similar to all languages, evolves constantly. One area that seems to be changing at the moment is that of passive use, which is the subject of ongoing research. Cultural differences may also have a role to play. For example, French scientists may have to overcome a basically Cartesian education.
\end{abstract}

Keywords: cultural difference; Journal des Sçavans; lingua franca; motivation; peer-review; Philosophical Transactions; publish or perish

\section{Introduction}

Publications have become an essential facet of academic activity in the contemporary world. Publication implies writing and the language in which academic research is couched has its specificities. Within that general area, different subgenres will also have their own particular traits. The academic, writing for the purpose of communicating his research, has to adhere to the linguistic features expected or face the possibility of seeing his articles refused by the gatekeepers of the journals in which he wishes to publish. While it would be impossible to be exhaustive on such a vast subject in the space of an article, in this paper I would like to consider certain aspects of this question.

I shall start by looking at how the academic article started in the late seventeenth century and what motivated the men involved. I shall do this in some detail since this is the basis from which the present situation has developed. I shall look, rather more briefly, at how this has evolved up to the present day with the relatively recent development of publication as a requirement for career advancement. In view of the current, though also fairly recent, development of English as an academic lingua franca, I shall consider the implications for non-Anglophone academics in terms of both the linguistic problems involved and the point of view of cultural differences resulting from their philosophical stance. As an example of the linguistic problems involved, I will consider the use of the passive voice. While this has long been recognized as a significant feature of scientific writing, recent research seems to show that changes in its use are in progress. In attempting to cover such a wide area, it is inevitable that some aspects will be treated in greater depth than others and some may be glossed over altogether. 
This may give the appearance of an article that is to some extent disjointed and uneven, but I feel it is useful to pose some of the pieces of this jigsaw puzzle that we have available without waiting until we can fill in the whole picture. If this spurs other researchers to help fill in some of the missing pieces of the picture, all the better.

\section{Where the Academic Research Article Started}

The birth of the academic research article can be dated from 1665. It was in that year that the first two academic periodicals appeared. The first in the field was the Journal des Sçavans, whose first issue appeared on 5 January. It was followed only two months later by the Philosophical Transactions, whose first issue appeared on 6 March [1]. Although these two publications appeared at virtually the same date and had the same objective of disseminating new knowledge, they were very different publications in many ways. The Journal des Sçavans was instigated by Colbert, Louis XIV's first minister. Colbert saw new knowledge as potentially dangerous: if new ideas can be revolutionary in say the scientific field, then they might infiltrate the political field and that had to be avoided at all cost. At the same time, Colbert hoped to harness advances in the arts and sciences to the task of augmenting the glory of the Sun King [2,3]. He had had the idea of a journal for several years. His first project had fallen through but Denis de Sallo, at Colbert's invitation, took up the challenge and, thus, became the first editor of the first academic periodical. His name did not appear on the first issue; a pseudonym was used instead. The reason why this was done is disputed, some claiming that it was a common practice at that time [4], some that it was out of modesty [5], and others that he thought it would be easier that way to get frank criticism [6-9]. The journal had a wide-ranging brief and the Notice to Readers (L'imprimeur au lecteur) in the first issue mentions book reviews, obituaries, reports of experiments and new inventions, and decisions of tribunals. In fact, book reviews made up most of the content: of the 29 items that were published in the 13 issues that de Sallo produced in 1665, 25 were book reviews, and this pattern continued in subsequent years under different editors. Nevertheless, its wide brief and the fact that it was directed at new knowledge in general meant that nothing was prima facie excluded, and so it covered the whole gamut of disciplines of the time [8].

In many ways, the Philosophical Transactions was quite different. This was the brainchild of Henry Oldenburg. Over the years, Oldenburg had gradually become the centre of a network of scientific correspondence. Such networks were not uncommon and, along with book publications, was considered one of the main ways of disseminating new knowledge. Consequently, the letters that Oldenburg received were not private; it was generally understood that the intention of their authors was that they should be copied, sent on, read at meetings, and so on $[10,11]$. This, together with the fact that he was one of the secretaries of the Royal Society placed him in a unique position. Oldenburg, unlike most of those with an interest in science who surrounded him, was not a man of private means and he was constantly short of money. His idea was to create a bulletin of scientific news that he could then sell as a means of increasing his income. He was aware of what was happening in France and indeed received a copy of the first issue of the Journal des Sçavans from which he read an extract at a meeting of the Royal Society on 11 January (only six days after it had appeared in Paris!). A letter from Sir Robert Moray to Christiaan Huygens mentions this and Oldenburg's plan to do something similar, though he would not touch on questions of law or theology [12]. On 1 March, the Royal Society endorsed Oldenburg's plans but, although the Philosophical Transactions had the Royal Society's imprimatur and could thus be published under their license and use their printers, it remained Oldenburg's private property and he retained full editorial and financial responsibility [7,13,14].

Thus, the Journal des Sçavans was state inspired and was even clandestinely financed by the state, dealt with all the academic disciplines of the period, and was made up mainly of book reviews. The Philosophical Transactions was a private venture, restricted basically to questions of science and technology, and was based on the contents of Oldenburg's correspondence. Thus, the very different historical contexts, the stability and security of the reign of Louis XIV in France, and in England the Restoration after half a century of chaos, produced two quite different periodicals, albeit with the 
same basic objective. This can even be traced to differences in the linguistic features found in the two publications. For example, analysis of the themes (in the linguistic sense of a clausal structure made up of a theme and a rheme) shows that the Journal des Sçavans has a thematic bias toward people (43\% of themes) and to a lesser extent texts (16\% of themes), whereas the object of study accounts for only $22 \%$ of themes. This can be linked to the fact that the Journal des Sçavans was made up mainly of book reviews. The thematic focus of the Philosophical Transactions, on the other hand, is the object of study ( $45 \%$ of themes) with people accounting for $27 \%$ and texts $7 \%$. This derives from the decision to restrict the content of the Philosophical Transactions to science and technology. Similarly, an analysis of the use of modality shows that while examples of epistemic modality are similar in the two publications (23\% of examples of modality in the Journal des Sçavans and 20\% in the Philosophical Transactions), there are more examples of dynamic modality in the Philosophical Transactions (76\% as opposed to $59 \%$ ) and more examples of deontic modality in the Journal des Sçavans (18\% as opposed to 4\%). This results from the greater interest in physical actions and events in the Philosophical Transactions, and the inclusion of disciplines where moral issues might be at stake, such as theology and law, in the Journal des Sçavans [1].

\section{The Motivation of Early Scientific Authors}

The question then arises as to what motivated those involved in the scientific activity of the early modern period and who wrote the articles that appeared in the Journal des Sçavans and the Philosophical Transactions. Almost all of these men were virtuosi, that is, they were gentlemen of private means for whom science was a leisure activity, even if for some it took up a great deal of their time $[15,16]$. Moreover, they rarely held university posts. At that time, it was generally thought that the development of humanity was similar to that of the human body and that humanity had been in its prime in the era of ancient Greece and Rome, and that by the seventeenth century it was already in its old age. It was thus thought that the "Ancients", notably, Aristotle in physics, Galen in medicine, and Ptolemy in astronomy, had reached the pinnacle of human achievement. Consequently, trying to outdo them was pointless; therefore, university endeavors were restricted to argumentation based on ancient texts and explaining their significance in the modern world. Experimentation and research had no place in such a scheme of things [17]. There were, of course, exceptions: Newton held a university post, although it was in mathematics, not physics. A little earlier, some future members of the Royal Society had been given university posts when Cromwell came to power. However, these were more or less political appointments and most members lost their post during the Restoration. Therefore, most of the members of the Royal Society and like-minded people worked outside the university system. There were a few who were not virtuosi, such as Henry Oldenburg and Robert Hooke [18,19], but they were the exception rather than the rule.

The situation in France was a little different due to the creation of the Académie Royale des Sciences in 1666. Unlike the Royal Society of London, which was "Royal" in name but received no financial support from the crown, the Académie Royale was established and maintained by the state. It was provided with premises in which to carry out its scientific activities and its members were paid a retainer by the state $[20,21]$.

It is clear that in the English situation, publishing research had no bearing on advancement in a career since for the vast majority of those involved there was no such thing as a scientific career. It seems probable that for most, the personal reputation and being recognized for one's achievements in what they believed to be a field that was new, experimental, and extending the bounds of human knowledge, was a major motivation. This was done very much in the spirit of Bacon who saw scientific endeavor as a way of improving the lot of humanity. Bacon was the maittre à penser of the members of the early Royal Society, and this was enshrined in Sprat's 1667 account and defence of the Royal Society [22]. Thus, personal kudos could be combined with the altruistic idea of helping humanity and it is all too human that this should be attractive. For a smaller number, questions of priority, particularly if commercial interests were involved, were of importance. Priority disputes were fairly 
frequent, one of the most significant being that between Robert Hooke and Christiaan Huygens on the invention of the spring-balance watch. In 1675, the Philosophical Transactions printed an item, translated from the Journal des Sçavans, in which Huygens described a spring-balance watch that he had invented [23]. Hooke riposted vigorously, claiming that he had invented just such a watch much earlier, and a bitter dispute developed. It seems that Hooke had indeed put forward the principles of this type of watch but that he had never carried it through to the production stage [18,19]. Other disputes have occurred, such as that with blood transfusion [24] and the well-known disagreement between Newton and Leibniz about the invention of calculus [25]. Although Newton manipulated the Royal Society, of which he was president, to underwrite his claims to priority [26], it is the symbolic system of Leibniz that has survived.

In France, the fact that the members of the Académie Royale were paid meant that the situation was significantly different. They might be considered to be the first professional scientists and since they were frequently called upon to advise the government on scientific matters, the first scientific civil servants. Obtaining an appointment at the Académie Royale was much sought-after and there was certainly rivalry among the prospective candidates. However, publishing does not appear to have played a role in this system. Although the work of the members of the Académie was published in its Mémoires, these publications were peculiar in two ways. First of all, the publications of the Académie, in its early years, were anonymous. Their work was considered to be collegial and was presented as the work of the group as a whole rather than of any particular individual [2,20,21]. As a consequence, those who did want personal recognition for their work turned to the Journal des Sçavans or, more occasionally, the Philosophical Transactions for publication. The second peculiarity was that the publications of the Académie Royale were not widely distributed. Since the Académie had been set up and was paid for by the crown, whatever it produced belonged to the King. Its purpose was to add to the glory of the Sun King through its scientific endeavour and this in itself was considered sufficient to legitimize its activities and results. The necessity of replication and the witnessing of experiments, so important to the English scientists, were superfluous for the members of the Académie and dissemination of their work was, thus, deemed unnecessary [2,27]. Although the Mémoires were published, they appeared only in limited luxurious editions, printed on fine paper, and bound in morocco leather. The volumes were considered to be the property of the King who used them as gifts for illustrious visitors. The members of the Royal Society found it difficult to understand why copies of the Mémoires were so difficult to obtain [21]. This situation lasted until 1699 when the reorganization of the Académie Royale included a decision to publish on a wider basis.

\section{Publish or Perish}

We have become so used to the "publish or perish" syndrome that it is perhaps useful to remember how recent the development is. It is probably no surprise to see that it played no part in the early development of the academic research article. Therefore, we may reasonably ask when it came into play. It is not easy to piece together the ways in which this has come about but the following are probably some of the pieces in this jigsaw puzzle. It is no doubt related to the gradual professionalization of science. The early Royal Society was not made up exclusively of men with a deep interest in scientific matters. Since it had no form of financial patronage, it relied almost exclusively on the fees paid by its members for its financial survival. Consequently, some members were elected more for their ability to pay than for any scientific prowess or even interest [14]. It has been estimated that as many as $30 \%$ of those who were nominally members took no active part in the scientific activities of the early Royal Society [28]. It was only in the mid-nineteenth century that the Royal Society finally became a totally scientific institution [14].

Another factor is the development of the peer review of papers submitted to scientific journals. Initially, the content of the early journals such as the Journal des Sçavans and the Philosophical Transactions were the personal decisions of their editors. In the case of the Philosophical Transactions, this remained the case until 1752 when it became the official organ of the Royal Society, and from then on its content 
was decided on by a committee. In 1832, this was put on a more formal footing and outside referees began to be used. In the case of the Académie Royale des Sciences, a form of peer review was built into its 1699 statutes [29]. These developed into the full peer-review system as we know it today [30,31].

Also relevant is the fact that as far as we can tell, there was little pressure to publish and there are several notorious cases of delayed publication by scientists such as Newton and Darwin. Newton's Opticks [32] was written over a fairly long period. He first published an article on a theory of light and colors in the Philosophical Transactions in 1672. This raised a controversy, which at times became fairly bitter, particularly on the part of Hooke, resulting in Newton, a natural recluse, going into his shell and refusing to communicate on the subject for several decades. The writing of Opticks was virtually complete before 1690, and even then Newton delayed publishing it. It was only in 1704, after Newton had become president of the Royal Society and after the death of Hooke (in 1703), that the book was finally published [33-35]. Curiously, the first edition in 1704 does not have Newton's name on the title page, though the preface does bear the initials I.N. [36]. Opticks ran to its fourth edition by 1730, which is the edition usually referred to today.

A second example is the notorious case of Darwin's The Origin of Species [30], which he started writing in 1836 but did not publish until 1859. It used to be widely believed that the long delay before publication was due to his fear of the repercussions it might have, including those of scientific colleagues and the possibility of religious persecution. However, recent studies suggest that he was determined to finish other work in hand, particularly work relating to the Beagle voyage and his major work on barnacles, before really getting down to writing his theory on natural selection [37,38]. It is also difficult to estimate to what extent the possibility of the imminent publication by Wallace of an almost identical theory played a part in precipitating the publication in 1859 . The question of how much he knew, and when, has been the subject of recent controversy [39-41]. At all events, Darwin knew that Wallace was working along the same lines as he was and, in any case, the question of evolution was "in the air" at that time; we know that in 1859 he published the single volume The Origin of Species that we now have, rather than taking the time to write the multi-volume work that he had originally intended [37].

Therefore, from the seventeenth century to the nineteenth getting things published rapidly does not seem to have been an important issue and this is despite the fact that in the course of the nineteenth century there was an explosion in the number of scientific periodicals, from about 100 at the beginning of the century to around 10,000 at the end [42]! This situation seems to have continued. Even as recently as the early 1970s, a sociologist could write in the abstract to one of his articles:

A large proportion of the scientific community publishes very little. The elite, prolific scientists are neither dependent on nor rewarded for the publication of their research, and most work by average scientists is hardly ever acknowledged [ . . . ]. [43] (p. 1119)

He goes on to argue that there is a charisma attached to scientific endeavor and it is the attraction of participating in this charismatic activity that motivates most scientists. Gupta [44] contends that in academia over the last 20 years there has been a move from a hierarchical communitarian situation to an egalitarian individualistic one; this he claims has produced

(i) an emphasis on a 'finished' product of obvious immediate utility, (ii) intense competition among peers, resulting in vicious, irrational reviewing of scientific papers and the promotion of 'cartels' among the scientific community. [44] (p. 391)

No doubt, the "publish or perish" syndrome fits into this scheme of things.

\section{Publishing and the Non-Anglophone Scientist}

The fact that publishing has become an imperative in the scientific world of today is compounded for the non-Anglophone scientist by the fact that English has become the international language of science. This poses problems for the language training of future science researchers [45] and for the 
linguistic help required by practicing scientists [46,47]. While it would seem that English is likely to remain the international language for the foreseeable future, it is worthwhile remembering that this has not always been the case and that the elevation of English to this state is relatively recent. A study of the languages in which the natural sciences were published over the period 1880 to 2005 shows that in 1880 English accounted for less than $40 \%$ of scientific publications and that by 1910 it had actually fallen to $30 \%$. From then on, the proportion of English publications rose but not always at the same speed: by 1930 it had risen fairly rapidly to a little less than $50 \%$, then more slowly to the mid-50\% by 1950. It was still in that range in 1970 but then rose dramatically to reach $80 \%$ before 1990 and over $90 \%$ by 2005. From 1910 to the mid-1920s, German had a greater share of scientific publications than English. In 1920, German accounted for over 40\% of publications, English a little over 30\%, and French just over 10\%. In the social sciences, the situation is less stark but English is still the dominant language, rising from a 48\% share of publications in 1951 to $76 \%$ in 2005 [48,49]. Hence, although English is likely to be the international academic language for the foreseeable future, that situation has nothing inevitable or unchangeable about it. Just as the present situation has been brought about by political and economic factors, it is not impossible that unforeseen future political and economic developments should lead to changes in the current situation.

It is sometimes thought that the position of English today can be compared to that which Latin once held. Although it is true that Latin was the universal academic language during the Middle Ages and into the early modern period when scientists began using vernacular languages in their articles, and subsequently in books, there is one essential difference. During this period, no one had Latin as his mother tongue; it was not the native language of anyone and there were no monolingual Latin speakers. There is much to be said for having a universal language for scientific communication. In fact, it would probably be much more difficult without one. If every scientist wrote in his native language, all scientists would have to learn several languages to keep up to date in their field. This is obviously not realistic. The difficulty about the present situation is precisely that a large, and probably the most powerful, sector of the scientific community has the universal language as its mother tongue, thus creating a sense of unfair advantage for those who have to communicate, usually with a struggle, in a language that is not their first language. The idea of an artificial or constructed universal language is an old one $[50,51]$. Towards the end of the nineteenth and beginning of the twentieth centuries, there were a number of attempts to create artificial universal languages. The only one of these to have survived in any form is Esperanto, which can hardly be said to have achieved universal status, but there were many others, including Volapûk, Ido, an offshoot of Esperanto, and, perhaps the most curious, Interlingua, an attempt to return to Latin, albeit in a vastly simplified form, "Latino sine flexione" [49]. Consequently, English is with us for at least the immediate future and that is the situation with which non-Anglophone scientists have to contend.

\section{Recent Changes in Scientific Writing}

Scientific language, similar to all languages, is in constant evolution [52] and so quite naturally is still changing. I shall take as an example the use of the passive voice, which has been considered a hallmark of scientific writing ever since Barber's seminal article in 1962 [53]. In a sample of issues of the Philosophical Transactions, the use of passive forms rose from a base of around $25 \%$ or less finite verbs in the early eighteenth century to over 30\% by 1980 [52]. Up to that point, there was no sign of the trend slackening but some recent work indicates that things might have altered since that date. In a series of articles [54-56], Seoane and her collaborators claim to have detected a decrease in passive use in scientific writing. They describe the decrease as "dramatic" [55] (p. 107) and claim that it is greater in American English than in British English. This is not due to colloquialization, as might have been thought, as other markers of colloquialization have not followed the same path. In [54], she considers and excludes the possibility that a move towards a more subjective style or that scientific writing is becoming more personal and author-centered explain the change. Similar points are made in [56] where scientific writing is contrasted with legal discourse. 
A study of recent scientific research articles does show that some sort of change seems to be underfoot. In the corpus that I was using for a recent study [57], I found sections written in the commonly expected passive form:

Phylogenies were constructed and dated in MRBAYES v. 3.2 .5 [39]. All phylogenetic analyses were run for 20 million generations, sampling every 1000 generations, with four chains and four independent runs for each analysis. The heating parameter was set to 0.05 for analyses that included fossils and 0.1 for analyses that did not include fossils. Priors were set using established protocols [27] (see electronic Supplementary Material S1), and convergence was judged using inbuilt diagnostics of MRBAYES and TRACER. [58] (p. 2) [my highlighting]

But I also found passages using the active voice with first-person pronoun subjects.

In this section, we illustrate the temporal evolution of the three generation-interval distributions (intrinsic, backward and forward) described by Equations (2.4), (2.11) and (2.8) with a simple epidemiological model.

In Figures 2 and 3 we use the well-known SEIR compartmental model (susceptible-exposedinfectious-recovered) where we include $n_{\mathrm{E}}$ (resp. $n 1$ ) exposed (resp. infectious) compartments in order to model realistic duration of latency and infectiousness with Erlang distributions (gamma distributions with integer shape parameter) [11]. We will refer to this model as an Erlang REIR and details of this model are given in §3. [59] (p. 4) [my highlighting]

These two extracts are both taken from the same issue of Proceedings of the Royal Society B for 2015. This study distinguishes between articles in the physical sciences (taken from the Proceedings of the Royal Society $A$, which deals with mathematical, physical, and engineering sciences) and the biological sciences (taken from the Proceedings of the Royal Society B, which deals with biological sciences). In this study of my (admittedly small) sample (and excluding papers by single authors), there does seem to be some evidence of a fall in the use of passive voice from 30\% of finite verbs in 1985 to $25 \%$ in 2015 for the Proceedings A sample, though this was not reproduced in the Proceedings B sample. On the other hand, the use of active voice with first-person pronoun subjects as a percentage of passivizable verbs rises considerably from 18\% in 1985 to 30\% in 2015 for Proceedings A, and from $9 \%$ to $18 \%$ in Proceedings B. Therefore, subject to verification on a larger sample, there does seem to be some evidence that there is increasing use of first-person pronoun plus active form at the expense of passive, though this development is clearer in the physical than the biological sciences. Among the possible factors favoring this change is the increasing use of non-Anglophone referees, which may be leading to a more permissive attitude toward the expected linguistic features in scientific writing. Indeed, in my sample, I noted several examples of English that I would have considered as non-standard in my native variety. In single-authored papers, first-person pronouns remain rare but even here I found one single-authored paper in my sample that used them extensively. Therefore, one can only presume that gatekeepers do not find this an impediment to publication.

However, it would probably be wrong to imagine that some scientific authors are simply using we + active where they would previously have used passive voice. Closer investigation shows that in the 2015 Proceedings A sample where we + active is used, 75\% of the verbs involved express a mental process (as used in Systemic Functional Linguistics [60,61] where the mental process includes cognitive verbs such as consider, estimate, and believe, and verbs of calculation or computer analysis, such as calculate, linearize, or derive). In comparison, only $4 \%$ of the we + active examples are of material process, that is, physical actions or events. In the 2015 Proceedings B sample, the corresponding figures are $54 \%$ for the mental process and $18 \%$ for the material process. Hence, the vast majority of personal pronoun subjects with active voice occur with mental process verbs and correspondingly few with 
material process verbs. This can, I think, be related to a phenomenon that began to occur in scientific writing towards the end of the nineteenth century in the physical sciences. Up to that time, articles in the physical sciences had been mainly experimental but from that date on mathematical modeling was introduced. This gathered pace during the twentieth century so that by the end of the century it had attained a significant, if not dominant, position [52]. There was little evidence of this phenomenon in the biological sciences up to 1980 but the biological sciences now seem to be following the same route as the physical sciences. The introduction of mathematical modeling has had effects on the linguistic features of scientific articles. This is notably in the types of themes (in the sense of thematic structure seen as distinction between theme and rheme) used to introduce clauses [60,61], which are now frequently of a mathematical nature, and the types of processes used with a strong increase in the use of mental processes of the mathematical calculation type. My hypothesis is that an author, where he is the agent, has a much closer relationship with a mental process, which is personal, cerebral and internal, than with a material process, which is external and involves entities in the external world. Hence, I would suggest that he is more likely to use a first-person pronoun with a mental process verb than with a material process verb [57]. Thus, it might be thought that the situation has become superficially easier for the non-Anglophone scientist in that he is freer to use the active voice more than he would have done previously, but at the same time he still has to learn when that can be done appropriately.

\section{Cultural Difference}

A further difference that might cause difficulties for the non-Anglophone scientist wishing to publish in English is that of cultural differences. That might be obvious where the differences are large, such as with the cultures of Asian countries. It might be less evident for geographical areas much closer to home. I shall take the example of Francophone scientists. This takes us back to the seventeenth century. When the Royal Society of London was founded in 1660, it was based on the ideas of Francis Bacon, that is, observation and experiment are paramount and precede any attempt to theorize [22]. A short time later this was given firm philosophical foundation by John Locke [62]. This empirical attitude meant that the Royal Society was deliberately distinguishing itself from the inductive methods of Descartes and his followers. One of the most striking examples of this is the very first phrase of Newton's Opticks: "My design in this Book is not to explain the Properties of Light by Hypotheses, but to propose and prove them by Reason and Experiments." [32] (p. 1) In other words, he was not going to set up a theory that he could then test against available evidence, which would have been the Cartesian approach, but he would carry out experiments on the basis of which he could build a theory. He was nailing his flag firmly to the empiricist mast. This difference between the empiricist stance of the Anglophone scientists and the Cartesian approach of those on the continent of Europe can be seen in the linguistic features of their writing [35]. Therefore, in the late seventeenth century, English and French scientists were working along different lines. It was only slowly that French scientists would gradually adopt the empirical approach. Maupertuis unsuccessfully attempted to promote Newton's ideas in France [63], but it was only after Voltaire and Emilie du Châtelet had taken up the cause and after the publication of Voltaire's Elements de la philosophie de Newton in 1738 that the tide really turned [64]. However, although French intellectuals in the hard sciences adopted the empirical model, this never extended to the humanities and social sciences; hence, even today, French academics in these fields tend to have a basically Cartesian approach. Consequently, when French scientists face the problem of writing in English, they not only have to overcome the language difficulties but also the fact that their education within the French system has been geared to producing a Cartesian mindset. To the best of my knowledge, this question is not addressed in the linguistic training that French scientists receive. As other academic fields move toward publication in English, French researchers in these areas will be faced with the same problems.

In terms of Holliday's [65] distinction between small culture and large culture, we might say that French and English scientists belong to the same small culture, that of the European scientific community. But this overlaps with two large cultures, French and English, and the scientists in question 
will, in general, belong to one or the other. Holliday claims that discourse is the product of small culture but here we see that large culture also has an effect on the discourse produced.

\section{Final Thoughts}

We have seen that the academic research article was born in 1665 . The motivation of these early scientists seems to have been self-fulfillment and, particularly where commercial interests might be involved, priority. Career advancement does not appear to have played a part even in France where members of the Académie Royale were, in a sense, state employees. Even in the nineteenth century, there was little pressure to publish rapidly and publications could sometimes be delayed for long periods. The rise of the publish or perish syndrome is relatively recent and probably the increasing professionalization of scientific activity and the peer review system in the selection of articles for publication have their part to play. For the non-Anglophone scientist, the position of English as the dominant, and for many virtually exclusive, language of publication poses problems. Although there may be a certain relaxation in the use of certain linguistic features, scientific authors still need to know when it is appropriate to use them. They need also to be aware of the cultural differences that separate them from the Anglophone mindset.

All language evolves and the language of the academic research article is no exception. Linguistic research can establish the present direction of change but it is impossible to foresee how long that direction will be maintained. I am doubtful about the possibility of forcing the development of language in a particular direction. Therefore, the linguistic analysis of developing academic language has a bright future and will be essential for non-Anglophone academics wishing to publish in English.

Conflicts of Interest: The author declares no conflict of interest.

\section{References}

1. Banks, D. The Birth of the Academic Article. Le Journal des Sçavans and the Philosophical Transactions 1665-1700; Equinox: Sheffield, UK, 2017, ISBN 13-978-1-78179-232-2.

2. Licoppe, C. The Crystallization of a new narrative form in experimental reports (1660-1690). The experimental evidence as a transaction between philosophical knowledge and aristocratic power. Sci. Context 1994, 7, 205-244. [CrossRef]

3. Gignoux, C.-J. Monsieur Colbert; Grasset: Paris, France, 1941.

4. Paris, G. Le Journal des Savants. J. Savants 1903, 5-34.

5. Cocheris, H. Histoire du Journal des Savants Depuis sa Fondation Jusqu'à nos Jours; Durand: Paris, France, 1860.

6. Camusat, D.F. Histoire Critique des Journaux; Nabu: Charleston, SC, USA, 2011; facsimile of 1734 edition, Bernard: Amsterdam, The Netherlands.

7. Kronick, D.A. A History of Scientific and Technical Periodicals. The Origins and Development of the Scientific and Technical Press 1665-1790; Scarecrow: New York, NY, USA, 1962.

8. Morgan, B.T. Histoire du Journal des Sçavans Depuis 1665 Jusqu'en 1701; PUF: Paris, France, 1928.

9. Birn, R. Le Journal des Savants sous l'ancien régime. J. Savants 1965, 1, 15-35. [CrossRef]

10. Gotti, M. Disseminating early modern science: Specialized news discourse in the Philosophical Transactions. In News Discourse in Early Modern Britain; Brownlees, N., Ed.; Peter Lang: Bern, Switzerland, 2006; pp. 41-70, ISBN 3-03910-805-0.

11. Kronick, D.A. The commerce of letters. Networks and invisible colleges in early modern science. In "Devant le Deluge" and Other Essays on Early Modern Scientific Communication; Kronick, D.A., Ed.; Scarecrow: Lanham, MD, USA, 2004; pp. 265-313, ISBN 0-8108-5003-6.

12. Bluhm, R.K. Henry Oldenburg, F.R.S. (c1615-1677). In The Royal Society: Its Origins and Founders; Hartley, H., Ed.; Royal Society: London, UK, 1960; pp. 47-56.

13. Hall, M.B. Henry Oldenburg. Shaping the Royal Society; Oxford University Press: Oxford, UK, 2002, ISBN 9780198510536.

14. Lyons, H. The Royal Society 1660-1940. A History of Its Administration under Its Charters; Cambridge University Press: Cambridge, UK, 1944. 
15. Stimson, D. Amateurs of science in 17th century England. Isis 1939, 31, 32-47. [CrossRef]

16. Stimson, D. Scientists and Amateurs. A History of the Royal Society; Henry Schuman: New York, NY, USA, 1948.

17. Jones, R.F. Ancients and Moderns. A Study of the Rise of the Scientific Movement in Seventeenth-Century England; Dover: New York, NY, USA, 1982, ISBN 0-486-24414-8.

18. Chapman, A. England's Leonardo. Robert Hooke and the Seventeenth-Century Scientific Revolution; Institute of Physics: Bristol, UK, 2005, ISBN 0-7503-0987-3.

19. Jardine, L. The Curious Life of Robert Hooke. The Man Who Measured London; Harper: London, UK, 2003, ISBN 0-00-715175-6.

20. Hahn, R. The Anatomy of a Scientific Institution. The Paris Academy of Sciences, 1666-1803; University of California Press: Berkley, CA, USA, 1971, ISBN 0-520-05738-4.

21. Hirschfield, J.M. The Académie Royale des Sciences (1666-1683): Inauguration and Initial Problems of Method; Arno: New York, NY, USA, 1981, ISBN 0-405-13857-1.

22. Sprat, T. History of the Royal Society of London for the Improving of Natural Knowledge; Kessinger: Whitefish, MT, USA, 2003; facsimile of 1667 edition, J. Martyn: London, UK.

23. Banks, D. Translating the academic article in the late seventeenth century. Evidence from the Journal des Sçavans and the Philosophical Transactions. In Proceedings of the 27th European Systemic Functional Linguistics Conference, Salamanca, Spain, 29 June-1 July 2017.

24. Hall, A.R.; Hall, M.B. The first human blood transfusion: Priority disputes. Med. Hist. 1980, 24, 461-465. [CrossRef] [PubMed]

25. Fara, P. Newton. The Making of Genius; Picador: London, UK, 2002, ISBN 0-330-37588-1.

26. Gleick, J. Isaac Newton; Fourth Estate: London, UK, 2003, ISBN 0-00-71617-7.

27. Hunter, M. The Royal Society and Its Fellows 1660-1700. The Morphology of an Early Scientific Institution; British Society for the History of Science: Chalfont St. Giles, UK, 1982, ISBN 0-906450-03-9.

28. Biagioli, M. From book censorship to academic peer review. Emerg. J. Study Media Compos. Cult. 2002, 12, 11-45. [CrossRef]

29. Atkinson, D. Scientific Discourse in Sociohistorical Context. The Philosophical Transactions of the Royal Society of London, 1675-1975; Lawrence Erlbaum Associates: Mahwah, NJ, USA, 1999, ISBN 0-8058-2086-8.

30. Darwin, C. The Origin of Species; Penguin: Harmondsworth, UK, 1986, ISBN 0-14-043205-1.

31. Despreaux, S.E. Fit to print? Referee reports on mathematics for the nineteenth-century journals of the Royal Society of London. Notes Rec. R. Soc. 2011, 65, 233-252. [CrossRef]

32. Newton, I. Opticks or a Treatise of the Reflections, Refractions, Inflections $\mathcal{E}$ Colours of Light, 4th ed.; Dover: New York, NY, USA, 1979, ISBN 0-486-60205-2.

33. White, M. Isaac Newton. The Last Sorcerer; Fourth Estate: London, UK, 1998, ISBN 1-85702-706-X.

34. Shapiro, A.E. Newton's experiments on diffraction and the delayed publication of the Opticks. In Isaac Newton's Natural Philosophy; Buchwald, J.Z., Cohen, L.B., Eds.; MIT Press: Cambridge, MA, USA, 2001; pp. 47-76, ISBN 0-262-02477-2.

35. Banks, D. Emerging scientific discourse in the late seventeenth century: A comparison of Newton's Opticks, and Huygens' Traité de la lumière. Funct. Lang. 2005, 12, 65-86. [CrossRef]

36. Cohen, I.B. The case of the missing author: The title page of Newton's Opticks (1704), with notes on the title page of Huygen's Traité de la lumière. In Isaac Newton's Natural Philosophy; Buchwald, J.Z., Cohen, L.B., Eds.; MIT Press: Cambridge, MA, USA, 2001; pp. 15-46, ISBN 0-262-02477-2.

37. Van Wyhe, J. Mind the gap: Did Darwin avoid publishing his theory for many years? Notes Rec. R. Soc. 2007, 61, 177-205. [CrossRef]

38. Odling-Smee, L. Darwin and the 20-year publication gap. Nature 2007, 446, 478-479. [CrossRef] [PubMed]

39. Smith, C.H. A further look at the 1858 Wallace-Darwin mail delivery question. Biol. J. Linn. Soc. 2013, 108, 715-718. [CrossRef]

40. Smith, C.H. Wallace, Darwin and Ternate 1858. Notes Rec. 2014, 68, 165-170. [CrossRef]

41. van Wyhe, J.; Rookmaaker, K. A new theory to explain the receipt of Wallace's Ternate essay by Darwin in 1858. Biol. J. Linn. Soc. 2012, 105, 249-252. [CrossRef]

42. Shuttleworth, S.; Charnley, B. Science periodicals in the nineteenth and twenty-first centuries. Notes Rec. 2016, 70, 297-304. [CrossRef]

43. Gustin, B.H. Charisma, recognition and the motivation of scientists. Am. J. Sociol. 1973, 78, 1119-1134. [CrossRef] 
44. Gupta, S. How has publishing changed in the last twenty years? Notes Rec. 2016, 70, 391-392. [CrossRef]

45. Salager-Meyer, F. Languages for Specific Purpose in the Third World. In Applications and Implications of Current LSP Research; Brekke, M., Andersen, Ø., Dahl, T., Myking, J., Eds.; Fagbokforlaget: Bergen, Norway, 1994; Volume 1, pp. 113-132.

46. Birch-Bécaas, S. From Author to Reviewer to Editor: Negotiating the claim in a scientific article. A study of French researchers publishing in English. ASp 1997, 15/18, 397-408.

47. Cooke, R. Learning to publish in English: How can French researchers bridge the gap? ASp 1993, 1, $463-475$. [CrossRef]

48. Ammon, U. Linguistic inequality and its effects on participation in scientific discourse and on global knowledge accumulation-With a closer look at the problems of the second-rank language communities. Appl. Linguist. Rev. 2012, 3, 333-355. [CrossRef]

49. Gordin, M.D. Scientific Babel. The Language of Science from the Fall of Latin to the Rise of English; Profile Books: London, UK, 2015, ISBN 978-1-78125-114-0.

50. Eco, U. La Recherche de la Langue Parfaite Dans la Culture Européenne; Manganaro, J.-P., Translator; Seuil: Paris, France, 1994, ISBN 2-02-012596-X.

51. Slaughter, M.M. Universal Languages and Scientific Taxonomy in the Seventeenth Century; Cambridge University Press: Cambridge, UK, 1982, ISBN 978-0-521-13544-3.

52. Banks, D. The Development of Scientific Writing. Linguistic Features and Historical Context; Equinox: London, UK, 2008, ISBN 978-1-84553-316-8.

53. Barber, C.L. Some Measureable Characteristics of Modern Scientific Prose. In Contributions to English Syntax and Philology; Behre, F., Ed.; Almqvist \& Wiksell: Stockholm, Sweden, 1962; pp. 21-43.

54. Seoane, E. Changing styles: On the recent evolution of scientific British and American English. In Syntax and Grammatical Norms: English from 1500-2000; Dalton-Puffer, C., Kastovsky, D., Ritt, N., Schendl, H., Eds.; Peter Lang: Bern, Switzerland, 2006; pp. 191-209.

55. Seoane, E.; Loureiro-Porto, L. On the colloquialization of scientific British and American English. ESP Cult. 2005, 2, 106-116.

56. Seoane, E.; Williams, C. Changing the rules: A comparison of recent trends in English in academic scientific discourse and prescriptive legal discourse. In Diachronic Perspectives on Domain-Specific English; Dossena, M., Taavitsainen, I., Eds.; Peter Lang: Bern, Switzerland, 2006; pp. 255-276.

57. Banks, D. The extent to which the passive voice is used in the scientific journal article, 1985-2015. Funct. Linguist. 2017, 4. [CrossRef]

58. Puttick, M.N.; Thomas, G.H. Fossils and living taxa agree on patterns of body mass evolution: A case study with Afrotheria. Proc. R. Soc. B 2015, 282. [CrossRef] [PubMed]

59. Champredon, D.; Dushoff, J. Intrinsic and realized generation intervals in infectious-disease transmission. Proc. R. Soc. B 2015, 282. [CrossRef] [PubMed]

60. Halliday, M.A.K.; Matthiessen, C. Halliday's Introduction to Functional Grammar, 4th ed.; Routledge: Abingdon, UK, 2014, ISBN 978-1-444-152-678.

61. Banks, D. Introduction à la Linguistique Systémique Fonctionnelle de L'anglais; L'Harmattan: Paris, France, 2005, ISBN 2-7475-8583-2.

62. O'Connor, J. John Locke; Dover: New York, NY, USA, 1967, ISBN 486-21746-9.

63. Bousquet, C. Maupertuis. Corsaire de la Pensée; Seuil: Paris, France, 2013, ISBN 978-2-02-107639-4.

64. Le Ru, V. Voltaire Newtonien. Le Combat d'un Philosophe Pour la Science; Vuibert/ADAPT: Paris, France, 2005, ISBN 2-7117-5374-3.

65. Holliday, A. Small cultures. Appl. Linguist. 1999, 20, 237-264. [CrossRef]

(C) 2018 by the author. Licensee MDPI, Basel, Switzerland. This article is an open access article distributed under the terms and conditions of the Creative Commons Attribution (CC BY) license (http:/ / creativecommons.org/licenses/by/4.0/). 